\title{
El viaje de Vicente Lombardo Toledano al mundo del porvenir
}

Daniela Spenser

El artículo sigue el itinerario del viaje de Vicente Lombardo Toledano a la Unión Soviética y coloca la exposición del viajero mexicano en una perspectiva más amplia. Examina el entusiasmo y el temor que las conferencias de Lombardo Toledano despertaron a su regreso, en el otoño de 1935, dadas las peculiares circunstancias de México y del mundo, cuando la élite política y la población estaban divididas entre defensores y adversarios del cardenismo. Indaga hasta qué punto Lombardo Toledano proyectó su agenda política para la sociedad mexicana en sus conferencias y en la defensa de la Unión Soviética.

PaLABRAS ClaVE: Vicente Lombardo Toledano, Lázaro Cárdenas, Unión Soviética

The Journey of Vicente Lombardo Toledano to the World of the Aftertime

The article follows the itinerary of Vicente Lombardo Toledano to the Soviet Union and puts the ideas of the Mexican traveller into a broader perspective. It explores the enthusiasm and the fears that on Lombardo Toledano's return in the fall of 1935 his conferences provoked in the peculiar circumstances of Mexico and the world, when the political elite and the population were divided between supporters and opponents of Lázaro Cárdenas. The article inquires into the degree to which Lombardo Toledano's conferences projected his political agenda for Mexican society and as a defense of the Soviet Union.

KEYWORDS: Vicente Lombardo Toledano, Lázaro Cárdenas, Soviet Union

DANIELA SPENSER: Centro de Investigaciones y Estudios Superiores en Antropología Social-Distrito Federal, México spenser@prodigy.net.mx 
El capitalismo mundial, aterrorizado por el desenlace inevitable de la lucha que se ha iniciado entre el régimen socialista triunfante y el sistema capitalista en completa bancarrota, ha recurrido a toda clase de medios para ocultary desprestigiar ante los ojos del proletariado que se rebela ya ante su crítica situación el resultado grandioso de los esfuerzos realizados de la ur $\mathbf{5 s}$, pero no serán seguramente las calumnias ideadas por la prensa burguesa las que podrán detener la marcha triunfal del régimen de los soviets ${ }^{1}$.

$\mathrm{E}$ 1 mundo occidental de la primera mitad de la década de 1930 estaba desolado tras la crisis económica de 1929 que provocó el desempleo de millones de trabajadores, hombres y mujeres. En 1933, la llegada de Adolf Hitler al poder en Alemania presagiaba un renovado belicismo y la barbarie. La depresión en el mundo capitalista trajo consigo un aumento en el interés por la Unión Soviética, aparentemente el lado opuesto de Alemania. Intelectuales de distintas ideologías progresistas y obreros fabriles fijaron sus ojos en la Unión Soviética, supuestamente sustraída de los desastres económicos y políticos en los que se sumía el mundo capitalista. La URSS parecía inmune a las crisis económicas, luego de más de una década de experimentar en la construcción de una sociedad y un sistema económico y político diferentes al occidental. Muchos fueron a constatarlo con sus propios ojos, entre ellos Vicente Lombardo Toledano y su amigo Víctor Manuel Villaseñor, quienes viajaron a la Unión Soviética en el verano de 1935 para conocer de cerca aquel experimento.

Lombardo Toledano era un destacado abogado y dirigente sindical que actuaba como enlace entre el mundo del trabajo y la élite gobernante en aras de crear y fortalecer sindicatos en un ambiente adverso. Villaseñor, miembro de una familia porfirista, era un economista educado en Estados Unidos y formaba parte de la élite intelectual posrevolucionaria; participó junto con Lombardo Toledano en la creación de instituciones obreras y estatales. Cuando ambos viajaron a la URSS, se consideraban mar-

\footnotetext{
${ }^{1}$ Vicente Lombardo Toledano y Víctor Manuel Villaseñor, "Situación de la clase trabajadora de México e impresiones de nuestro viaje a la URSS", París, 2 de octubre de 1935, Fondo Histórico Lombardo Toledano (FHLT), legajo 267.
}

xistas. A su regreso, dieron varias conferencias en la capital del país, las cuales despertaron tanto entusiasmo como airadas protestas. Los viajeros mexicanos presentaron un cuadro, común en la época, en el que los éxitos en la construcción del socialismo en la URSS superaban con creces sus costos en recursos y esfuerzo humano. No fueron sólo las conferencias las que provocaron el entusiasmo o el escándalo en el México del inicio de la presidencia de Lázaro Cárdenas, sino el vaticinio de Lombardo Toledano de que la suerte de la Unión Soviética era el porvenir de la humanidad entera.

En lo que sigue, introduciré someramente algunos escritos e ideas de varios viajeros a la URSS en las décadas de 1920 y 1930 para comparar sus observaciones con las de Lombardo Toledano; además, analizaré la exposición del mexicano en una perspectiva más amplia. Examinaré el entusiasmo y el temor que las conferencias de Lombardo Toledano y Villaseñor despertaron en las peculiares circunstancias de México y del mundo en el otoño de 1935, cuando la élite política y la población estaban divididas entre defensores y adversarios del cardenismo, corriente con la que él fue identificado. Indagaré hasta qué punto Lombardo Toledano proyectó su agenda política para la sociedad mexicana en sus conferencias y en la defensa de la URSS. Examinaré cómo el discurso del viaje influyó en el México de la segunda mitad de 1935 y cómo contribuye a entender la crítica coyuntura suscitada por el conflicto entre el grupo conservador y el progresista de la élite gobernante, reflejando dos concepciones de hacer la política.

\section{LA UNIÓN SOVIÉTICA, SUS SIMPATIZANTESY SUS CRÍTICOS}

En las décadas de 1920 y 1930, decenas de intelectuales, políticos, dirigentes obreros y simpatizantes visitaban la Unión Soviética para conocer el experimento de la ingeniería. El alemán Walter Benjamin la visitó en 1926; el irlandés George Bernard Shaw, el aristócrata del intelecto, en 1931. Los intelectuales estadounidenses Theodore Dreiser, John Dos Passos, John Dewey y Waldo Frank se dieron una vuelta por el este europeo a finales de la década 


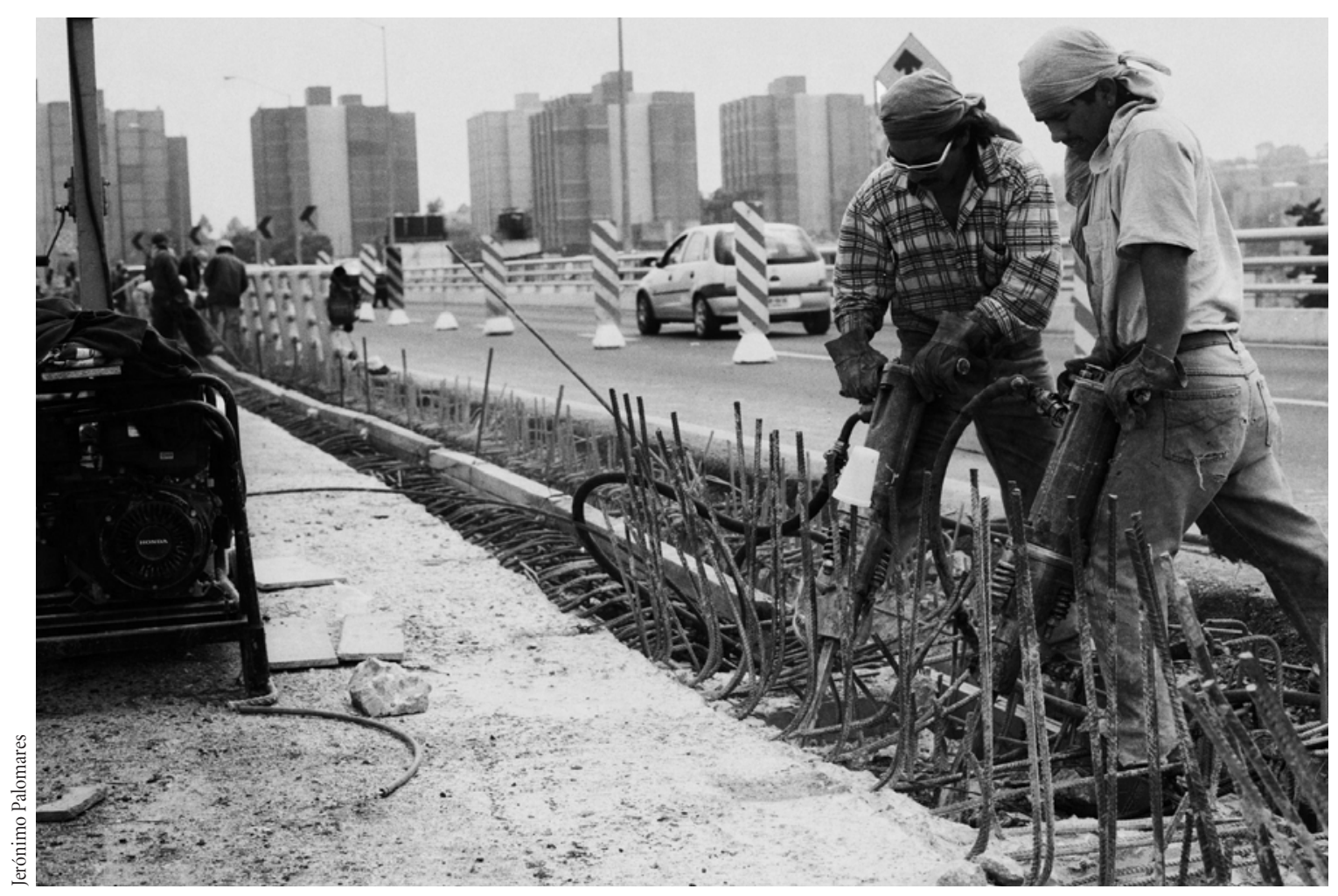

Construcción del segundo piso del Periférico, ciudad de México, 2005.

de 1920 y principios de la siguiente. El francés Romain Rolland fue huésped distinguido de los soviéticos en 1935, mismo año en que los sindicalistas británicos Beatrice y Sidney Webb publicaron un libro en el que manifestaron, no sin crítica a la "enfermedad de la ortodoxia", que en la URSS habían descubierto una nueva civilización. Sir Walter Citrine, el secretario general de Trades Union Congress, visitó la URSS en 1925 y nuevamente en 1935, y André Gide, quien se encontraba a la sazón en la cumbre de la gloria literaria en Francia, viajó allí en junio de 1936. Todos dejaron sendas descripciones de sus viajes. Además, un sin fin de delegados de partidos comunistas y de sindicatos obreros llegaban a la Unión Soviética en búsqueda de soluciones a los males sociales que padecían en sus respectivos países (Benjamin, 1988; Dreiser, 1928; Engerman, 2006; Shaw, 1964; Morgan, 2006; Frank, 1932; David-Fox, 2005; Gide, 1936; Citrine, 1936; Berger, 1935; Furet, 1995: 328-336).
En general, los visitantes fueron acogidos por sus anfitriones con generosidad, sus gastos fueron cubiertos por el gobierno soviético y los pasearon de un lado a otro del país. Para halagar a Gide, por ejemplo, el gobierno soviético imprimió 3000 tarjetas postales con su retrato y a su llegada le organizó una recepción regia, sin dejar nada al azar en el encuentro del refinado escritor con la cruda realidad de la URSS. Los soviéticos buscaban enseñarle a los visitantes lo que consideraban los frutos más acabados o en proceso de madurar del socialismo en construcción, para que se llevaran la mejor impresión y la divulgaran en sus países de origen, pues había que proyectar la imagen de una nación que de atrasada se convertía en la luz que iluminaba el camino hacia el futuro (David-Fox, 2003: 300-335; Furet, 1995: 330).

La reacción frente a la realidad soviética varió de visitante a visitante. Walter Benjamin anotó en su diario de viaje que existía una efervescencia literaria en medio del 
acoso y las restricciones ideológicas impuestas por los nuevos mandarines de la cultura. En 1927, después de haber publicado An American Tragedy, en la que criticó el descarnado materialismo del sueño americano, Theodore Dreiser admiró el empuje hacia la modernización de la industria soviética pero no se pudo explicar el deplorable y sucio estado de los baños, los hoteles, los restaurantes y las estaciones de tren, y el descuidado aspecto de la gente, como no fuera por falta de cultura cívica. En su viaje de 1928, el filósofo estadounidense John Dewey quedó impresionado por los avances en la educación, mientras que a su esposa la conmovió la mala vestimenta de la población. A pesar de la negligencia que Waldo Frank notó en las calles, no podía olvidar que se encontraba en la tierra de gigantes literarios como Nikolai Gogol, Lev Tolstoy, Fiodor Dostoyevsky y Konstantin Aksakov, cuyos protagonistas "habían viajado de Rusia a la mente del Occidente" (David-Fox, 2003: 317; Frank, 1932: 9).

En efecto, una de las cosas que asombró a los visitantes extranjeros fue el aspecto de pobreza, los edificios derruidos o las construcciones nuevas que no embellecían las ciudades y, sobre todo, la presencia de niños desamparados en las calles. También notaron, con satisfacción, lo que destacaron como la democratización de los espacios públicos, como el caso de Leningrado, donde el imperial Petersburgo y sus palacios se convirtieron en lugares accesibles para toda la población. La vieja ciudad no se modificó, pero los patios de los palacios que antes eran cocheras y establos de la burguesía palaciega ahora eran guarderías. Según la visión literaria de Frank, la Rusia soviética y la de antaño estaban fundidas (Frank, 1932: 14-15, 101).

Walter Citrine, secretario general de la central obrera británica, fue uno de los agasajados por la Unión Soviética que pudo apreciar el cambio cualitativo entre su primera visita en 1925 y la segunda en 1935. Citrine creía que una de las principales tareas de los sindicatos era el mejoramiento de las condiciones materiales de los trabajadores sin derrocar el capitalismo. El sindicalista británico hablaba de la transformación gradual del capitalismo, la cual no podía lograrse mediante conflictos industriales sino por medio de la continua presión de los obreros or- ganizados bajo un liderazgo unificado, extendiendo la autoridad y la responsabilidad de los sindicatos a la esfera de la administración industrial (Van Goethem, 2000: 109-112).

El bienestar integral de los obreros era primordial para Citrine, quien objetó todo lo que impedía alcanzarlo. Antiguo electricista, el dirigente miraba las condiciones sociales en la URSS desde la perspectiva de los obreros: sus necesidades y los satisfactores materiales y educativos que tenían a su disposición. Si en su libro incluyó tantas comparaciones entre los salarios de los obreros soviéticos y los británicos fue para mostrar qué podían comprar con lo que se les pagaba por el trabajo desempeñado. Su ojo experto se fijó en la calidad del trabajo obrero. Citrine advirtió una y otra vez trabajo de baja calidad en aras de aumentar la producción, cuyo ritmo fue impuesto a los obreros y en nada se distinguía del trabajo a destajo. Le impresionaban las estadísticas de la producción, pero cuando veía el acabado de las puertas, de los muebles o de los edificios, se lamentaba de que la calidad empeoraba a medida que aumentaba la cantidad de los productos. Citrine condenó el productivismo soviético y rechazó la asimilación de los sindicatos al Estado, pues no actuaban con libertad e independencia, y sin ellas se cancelaba el sindicalismo legítimo y defensor de los intereses de los obreros. En consecuencia, le preocupaba la aparición de una élite de la clase obrera soviética encargada de la organización de la economía.

Citrine no fue un observador imparcial, pero tampoco fue a la URSS para comprobar verdades sino para buscarlas y averiguar, con la curiosidad de alguien convencido de las bondades del capitalismo, las ventajas del sistema en construcción. Como otros observadores, fue sensible a la mejoría en la vida de las mujeres, a las que el Estado proveía de guarderías y otorgaba licencias de maternidad, y quienes trabajaban en condiciones de equidad con los hombres, tanto en salario como en dificultad laboral. Si por un lado los niños de la calle constituían un fenómeno que a todos los observadores llamaba la atención, la felicidad y el bienestar de los niños en las guarderías también sorprenderían a los visitantes.

Las incomodidades de la vida cotidiana absorbieron gran parte de su atención: la falta de baños y de agua ca- 
liente, el hacinamiento en los departamentos donde antes vivía una familia y en los que ahora varias familias rentaban un cuarto cada una. La oferta de víveres le parecía limitada y mal presentada. Las largas filas en las tiendas eran un fenómeno notorio, así como la pobreza en la vestimenta de los hombres, mujeres y niños. En cambio, en las fábricas observó comedores bien equipados y con buena comida, y sobre todo quedó gratamente impresionado con las bibliotecas y las estancias de descanso para los obreros. El balance final era que el Estado socialista debía ser más humano y no una carrera productivista a expensas del bienestar de la población trabajadora (Citrine, 1936: 289-362).

Desde una perspectiva intelectual, Andre Gide se acercó a la cotidianidad soviética después de haber cambiado de incondicional admirador a crítico durante su estancia en junio de 1936. Como muchos de sus contemporáneos, Gide vio en el primer plan quinquenal (1928-1932) la antítesis del desorden capitalista y se formó una imagen de la URSS como la patria del desarrollo y la cultura. Durante su visita confirmó algunas impresiones que tenía y rechazó otras. El escritor admiró la plenitud que disfrutaban los niños en los campamentos, así como el experimento en la rehabilitación de criminales al hacerse responsables de su comunidad, al proveerlos de fábricas, clubes y bibliotecas con la convicción de que la delincuencia era socialmente inducida y podía ser remediada por la misma vía. Por el otro lado, lo afligió la presencia de niños harapientos en las calles, ante lo cual las autoridades parecían impotentes. La policía los recogía, pero regresaban u otros tomaban su lugar. Sin embargo, Gide fue testigo de la bondad hacia uno de los niños, recogido por un campesino, que le recordó un cuento de Dostoyevsky y le permitió hacer un puente mental entre la literatura rusa y el presente, con lo cual pudo atenuar la ruda realidad con la que se topó en la Unión Soviética (Gide, 1936: 81-94, Furet, 1995: 328-334).

No obstante las bondades que anotó Gide, condenó con vehemencia el control administrativo de la cultura. Fue a la URSS buscando la creatividad revolucionaria, y en cambio encontró a aduladores de Stalin que producían banalidades. Según el escritor, una obra de arte no se podía crear de acuerdo con una doctrina sino "formulan- do preguntas que anticipan las del futuro y contestando preguntas que todavía no han sido formuladas"(Gide, 1936:81). La revolución triunfante debería ofrecerle al artista la libertad por encima de cualquier otra cosa.

En octubre de 1936, una vez publicado en París, el Retour de l'URSS de Gide causó furor y fue un éxito comercial gracias a la fama del escritor y a la curiosidad de los lectores por el acontecimiento político-literario. Los COmunistas acusaron a Gide de privilegiar la vida intelectual de la URSS sobre la cotidiana y de menospreciar el pasado ruso que pesaba sobre el presente y sin el cual éste no se podía explicar. En respuesta, Gide publicó una posdata al primer libro sobre sus encuentros y los de sus compañeros de viaje con la gente en su vida cotidiana, y extrajo de la prensa oficial estadísticas y comentarios sobre la economía soviética para hacer frente a la crítica que su primer libro había despertado. Uno de los muchos datos dramáticos que citó fue la revocación del derecho de las mujeres al aborto, así como la mala calidad de los anticonceptivos, cuya consecuencia era la abstención de establecer lazos amorosos y nuevas familias. Presentó cifras sobre la pobreza, sobre la inadecuada educación, sobre la inasistencia de los niños a la escuela y la falta del pago oportuno de salarios a los maestros. Gide lamentó tener que transcribir esta evidencia estadística, pero escribió el segundo libro en protesta por la ceguera y la mala fe de quienes negaban los terribles resultados de la economía política del Estado soviético. Añadió información sobre los procesos fabricados en contra de los viejos dirigentes bolcheviques y sobre los miles de hombres y mujeres deportados de la capital soviética porque se les acusaba de estar relacionados con los crímenes inventados contra los primeros. Gide se desencantó con el proceso soviético y dejó de creer que se pudiera luchar por la democracia bajo la misma bandera que enarbolaba Josef Stalin (Gide, 1937:54-79; Furet, 1995: 329-334).

Aun para observadores que fueron a la Unión Soviética sin la intención de confirmar juicios preestablecidos, la realidad cotidiana de la población quedó en gran medida oculta. A la nomenclatura soviética no le interesaba que hubiera testigos de la inexistencia de la democracia obrera, del Estado-comuna que debió ser el sistema pero no 


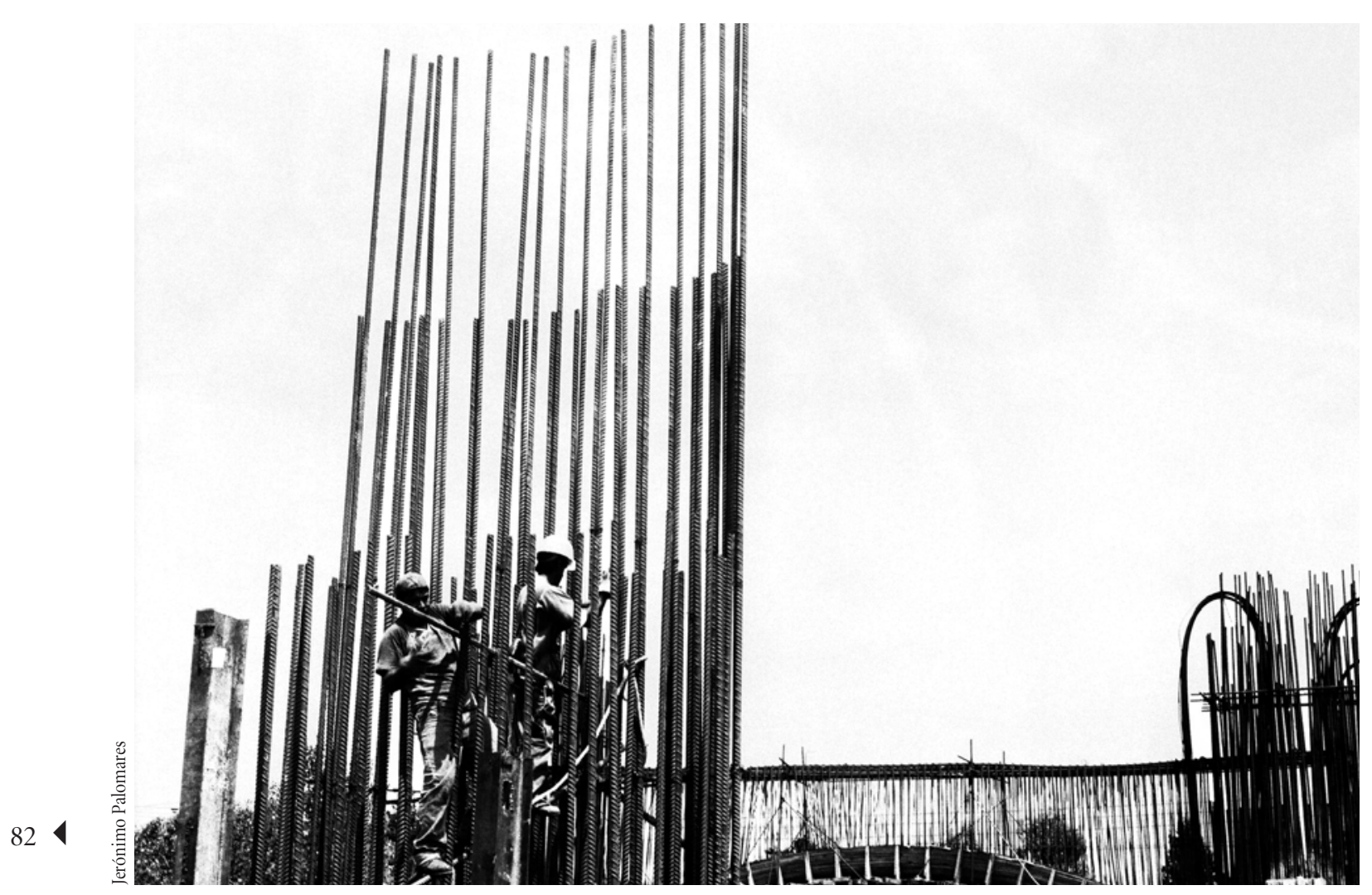

Construcción del segundo piso del Periférico, ciudad de México, 2005.

lo era, porque en su lugar se erigió un Estado "ebrio de su propio poder" que descansaba sobre la todopoderosa policía política y en una burocracia de ejecutantes privilegiados para los cuales el ser humano no contaba, según escribió en 1933 Víctor Serge desde Moscú a sus amigos en París. Serge, uno de los arquitectos del andamiaje institucional de la Rusia Soviética durante los primeros años de la revolución, en 1933 era un testigo de "la mentira que se respira como el aire" sobre el cumplimiento del plan quinquenal, el aumento de los salarios y de la seguridad del trabajador, así como el racionamiento del pan que conducía a la amargura, la desilusión y la pasividad de la población trabajadora, en una sociedad que no toleraba el valor cívico o la moralidad colectiva y que promovía la delación a cambio de un lugar para vivir, o para conseguir una carta de racionamiento de pan, y donde la gente se agolpaba para subirse a un tranvía. Ante un ambiente tan complejo — sigue Serge — los viajeros extranjeros eran incapaces de penetrar la realidad de una revolución socialista enferma y "quienes cierran sus ojos ante el mal se convierten en sus cómplices por ignorancia, ceguera, pusilanimidad o interés" (Serge, 1933) ${ }^{2}$.

Si bien es cierto que en 1935 la situación de consumo de alimentos mejoró respecto del desastroso 1933, el peor de la década, cuando en promedio un obrero en Moscú no consumía grasas y se mantenía con poca leche, algo de fruta y la quinta parte de lo que consumía de carne y pescado al principio del siglo, en 1936 la situación volvió a agravarse debido a la mala cosecha que condujo a parte del país a condiciones de hambruna y provocó la huida de los campesinos de las granjas colectivas y lar-

\footnotetext{
${ }^{2}$ Agradezco a Adolfo Gilly el documento y su crítica de mi pusila-
} nimidad. 
gas filas para comprar pan. Con el extraordinario crecimiento de las ciudades, 60\% entre 1926 y 1933, se agudizó también la carencia de vivienda y los servicios resultaron insuficientes. La escasez favoreció la aparición del mercado negro y la corrupción en las instituciones estatales encargadas de la distribución de los bienes de consumo y de la vivienda (Fitzpatrick, 1999: 41-66).

Era tiempo de utopías, de la transformación humana y natural por medio de la industrialización y la moderna tecnología, un periodo llamado "la construcción del socialismo"; un colosal mundo soviético por venir que los héroes, nacidos con la Revolución en 1917, hacían posible en el presente, con su capacidad para remodelar a los hombres y mujeres, incluyendo a los criminales, y transformarlos en buenos ciudadanos soviéticos. Uno de los subproductos de esos nuevos tiempos fue una vertiginosa movilidad social del campo a las ciudades, y de la agricultura a las fábricas, de todos aquellos hombres y mujeres que no fueron impedidos de hacerlo por la introducción de pasaportes internos. Este símbolo del despotismo del antiguo régimen fue legalizado en diciembre de 1932 para impedir que las personas políticamente no confiables se establecieran en las ciudades, obtuvieran residencia y empleo. La medida fue aplicada a campesinos sin calificación, a sacerdotes y a la desposeída burguesía, a profesionistas e intelectuales que estaban fuera del partido bolchevique y a sus familias, tanto hijos como padres. La deportación y el exilio, castigos del régimen zarista, fueron restablecidos a finales de la década de 1920 para todos aquellos que el gobierno y el partido consideraban indeseables. De entre los dirigentes soviéticos opuestos a Stalin, Lev Trotsky fue el exiliado más prominente (Fitzpatrick, 1999: 67-88 y 115-138) $)^{3}$.

\section{LOS PREPARATIVOS DEL VIAJE}

Desde la perspectiva del materialismo histórico como el dogma de su vida, Lombardo Toledano estaba convencido de que el proletariado acabaría con el capitalis-

\footnotetext{
${ }^{3}$ La cotidianidad durante el periodo estalinista está documentada en Siegelbaum y Sokolov, 2000
}

mo y que ésta era la solución histórica para terminar con el régimen burgués. La Unión Soviética era el país donde la transición de una etapa histórica a otra superior estaba adelantada como en ningún otro lugar del planeta, y había que conocerla porque representaba el futuro para la humanidad. Lombardo Toledano era partidario de la consolidación del poder centralizado del Estado y en la persona de Stalin, de la racionalidad tecnocrática para conducir la economía y la sociedad, incluyendo los sindicatos obreros. En una conferencia impartida en Monterrey en abril de 1935 afirmó: "Vivimos actualmente en la terminación de un régimen social y en el principio de otro nuevo. El régimen capitalista es el que desaparece; el régimen socialista es el que lo reemplaza en la historia" ${ }^{4}$. En una entrevista que le hizo la revista Americas de Nueva York sobre el propósito de su viaje a la Unión Soviética, Lombardo Toledano contestó que le interesaba conocer de cerca "el régimen proletario" cuyos "procedimientos" no se podían aplicar en México mientras que no existiera el mismo régimen. Por lo pronto, en México "el proletariado" tenía que conocer a la URSS para defender "con energía este régimen único en el mundo", en una época en la que el régimen capitalista vivía "su última etapa histórica", pues laUnión Soviética "representa hoy el único manantial de la cultura verdaderamente universal del porvenir" 5 .

En mayo de 1935 llegaron a México el poeta Rafael Alberti y su esposa, la escritora María Teresa León. Españoles, comunistas y defensores de la República así como de la Unión Soviética, su presencia sirvió de puente para que por intermediación de los comunistas mexicanos se organizara el viaje de Lombardo Toledano a la URSS ${ }^{6}$. El

\footnotetext{
${ }^{4}$ Vicente Lombardo Toledano (VLT), "Bases filosóficas y principios científicos del socialismo", Monterrey, 8 de abril de 1935, FHLT, legajo 259; Lombardo Toledano, 1995 [1935]: 262.

${ }^{5}$ Consejo Nacional de la Confederación General de Obreros y Campesinos de México (CGOCM) a VLT, México, D. F., 1 de julio de 1935 VLT a Arturo Martínez Adame, México, D. F., 9 de julio de 1935; VLT a Humberto Lombardo Toledano, México, D. F., 10 de julio de 1935 , FHLT, legajo 265.

${ }^{6}$ Informe sobre el viaje de Rafael Alberti y María Teresa León por Estados Unidos, México y Centroamérica, marzo-octubre de 1935, Archivo Estatal Ruso de Historia Sociopolítica, fondo 495, registro 79, expediente 231; R. Ortiz, Secretariado del Caribe sobre el viaje de Vicente Lombardo Toledano a la URSS, dirigido probablemente a la oficina
} 
interés era mutuo. Los comunistas esperaban que el viaje sirviera para que los dirigentes de la Internacional Comunista (Comintern) en Moscú lo acercaran a su punto de vista. Lombardo Toledano era el dirigente indisputable de la central obrera, la Confederación General de Obreros y Campesinos de México (CGOCM), y los comunistas eran la vanguardia del proletariado, pero sin las masas obreras salvo los sindicatos bajo su influencia en la Confederación Sindical Unitaria de México (CSUM). Moscú era el lugar ideal para el acercamiento:

Yo pienso que ustedes deben hablar con él allá, con objeto de tratarlo en el plano que se requiere para estrechar más a las masas de la Confederación hacia nuestra línea. Es claro que la influencia de él en la Confederación tiene mucho arraigo, y cualquier cambio en la posición de Lombardo hacia nuestra política puede tener un reflejo en las masas de la Confederación ${ }^{7}$.

En cambio, Lombardo Toledano quería acercarse a los comunistas para contar con su aval para construir una central única en México que contara con la mayoría de los sindicatos en el país bajo su batuta, y para ello necesitaba que la Internacional Comunista reconociera su papel como dirigente obrero sin par. La Comintern debió tener sus propias razones para acceder al viaje de Lombardo Toledano y de sus acompañantes y luego para colmarlos de tantas atenciones en la URSS.

Lombardo Toledano quería aprovechar el viaje para acercarse en Europa a dirigentes sindicales del espectro más amplio antes de convocar a la creación de la Confederación de Trabajadores de México, lo que tenía programado organizar a su regreso. Su objetivo, además de la unificación de los dispersos sindicatos, "era su influencia eficaz sobre la masa campesina" en aras de luchar contra la explotación capitalista e imperialista ${ }^{8}$. Lombardo Toledano creía que:

\footnotetext{
de Nueva York, 8 de julio de 1935 (telegrama), Archivo Estatal Ruso de Historia Sociopolítica, fondo 534, reg. 7, exp. 397.

${ }^{7}$ Sin autor a Hernán Laborde, México, 16 de julio de 1935, Archivo Estatal Ruso de Historia Sociopolítica, fondo 495, reg. 108, exp. 181.

${ }^{8}$ VLT y Víctor Manuel Villaseñor, "Situación de la clase trabajadora de México e impresiones de nuestro viaje a la URSs", París, 2 de octubre de 1935, FHLT, legajo 267.
}

Ningún gobierno social-demócrata puede satisfacer plenamente los ideales de la clase trabajadora; por eso no exigimos al gobierno actual que haga el cambio histórico del régimen capitalista en que nos hallamos; pero sí le exigimos que las libertades consagradas en las leyes vigentes se mantengan, ya que esto nos permite desarrollarnos por nuestra propia cuenta para actuar en el momento histórico decisivo y propicio ${ }^{9}$.

Lombardo Toledano propagaba la idea de que los trabajadores (organizados y dirigidos por gente como él) tenían la fuerza para cumplir con su "objetivo histórico", que era derrocar el régimen burgués. Primero había que crear una central sindical como condición "para actuar en el terreno político" ${ }^{10}$. El momento propicio para actuar era el inicio del gobierno del presidente Lázaro Cárdenas.

Lombardo Toledano juzgó a Cárdenas, el militar de 40 años, como "un poco romántico e ingenuo, sincero y honrado, de ideas radicales imprecisas, y distanciado moralmente del grupo de hombres manejados incondicionalmente por Calles", un hombre bien intencionado pero sin ideas claras sobre el camino a seguir. Esta percepción motivó a Lombardo Toledano a medir la temperatura del ambiente político cuando encabezó el estallido de huelgas, confiando en que Cárdenas "le prestaría su apoyo [a la clase trabajadora], o por lo menos no la haría víctima de represiones violentas"11.

En efecto, los primeros seis meses del sexenio del presidente Cárdenas se caracterizaron por una ola de paros y huelgas que no se habían visto en los seis años anteriores. Tal como Lombardo Toledano anticipó, el presidente no reprimió ninguna huelga, aunque esperaba que Cárdenas no sólo fuera "amigo del proletariado" sino que diera un paso audaz, el cual no dio, de modo que no "se ha registrado ningún acto que pueda considerarse como 'revolucionario' o 'socialista". Lombardo Toledano desconfiaba de Cárdenas: "gobierno tolerante de las luchas

\footnotetext{
${ }^{9}$ VLT al doctor Enrique C. Enríquez, México, D. F., 27 de junio de 1935, FHLT, legajo 264 y VLT a Arturo Martínez Adame, México, D. F., 9 de julio de 1935, FHLT, legajo 265.

10 "Contestación al cuestionario formulado por la revista Americas", Nueva York, 26 de julio de 1935, FHLT, legajo 265.

${ }^{11}$ VLT, "El derrumbamiento del general Plutarco Elías Calles", manuscrito, julio de 1935, FHLT, legajo 265.
} 
obreras, falto de programa en los problemas vitales de México y propaganda demagógica para dar la impresión de gobierno radical, honesto y firme". Tampoco se hacía muchas ilusiones, pues "mientras subsista el actual régimen social, el Estado tendrá que ser, lógicamente, un aliado de la burguesía y un enemigo más o menos franco de los propósitos finales de la propia clase obrera" 12 .

El rayo que cayó del cielo para que Cárdenas definiera claramente su posición frente a los trabajadores organizados, según Lombardo Toledano, fueron las críticas en junio de 1935 del expresidente Plutarco Elías Calles, referente al supuesto caos en el país provocado por dirigentes como Lombardo Toledano en connivencia con el presidente. El 12 de junio Calles envió a los periódicos una declaración que cuestionaba las movilizaciones de los sindicatos y el apoyo del presidente Cárdenas a las huelgas. La crisis política que provocó la torpe intervención de Calles en el curso del nuevo régimen llevó a Lombardo Toledano a demostrar de manera fehaciente que la fuerza estaba en la calle y "con huelga general revolucionaria, si era preciso" ${ }^{3}$. Expresó a los periódicos: "Aprovecho esta ocasión para declarar que no soy sino un humilde agitador y que proseguiré en mi actitud, mientras exista, sirviendo a la causa del proletariado"14.

Lombardo Toledano, en nombre de la CGOCM, Francisco Breña Alvírez, dirigente del Sindicato Mexicano de Electricistas (SME) y varias agrupaciones obreras se reunieron para crear el Comité Nacional de Defensa Proletaria (CNDP) en respaldo al presidente. Además del SME y la CGOCM, el Comité juntó a la Confederación Sindical Unitaria de México (CSUM) y a varios sindicatos independientes, mientras que la Confederación Regional Obrera de México (CROM) y la Confederación General de Trabajadores (CGT) permanecieron leales a Calles (Basurto, 1983: 51-67; Middlebrook, 1995: 86-88).

La lógica de Lombardo Toledano era que si bien Cárdenas quería "entregar el gobierno al proletariado", esa posibilidad no existía mientras el nuevo gobierno estuviera lleno de "la casta parasitaria" que los trabajadores "echa-

\footnotetext{
${ }^{12}$ Idem.

${ }^{13} \mathrm{Idem}$.

${ }^{14}$ Idem.
}

rían a puntapiés de todos los puestos políticos". El futuro de México no dependía del país, sino del conflicto armado internacional, pero aun así Cárdenas "puede darnos sorpresas buenas: ya dio una" al excluir a los callistas de algunos puestos en su gobierno. La gran sorpresa que Lombardo Toledano esperaba era que Cárdenas “a la hora decisiva quiera jugarse la vida por la revolución verdadera, en vez de perderla a manos de los políticos profesionales"15. Por medio del Consejo Nacional de la CGOCM, Lombardo Toledano fue más lejos aún: "la actitud del general Calles significa para el proletariado de México la amenaza de perder hasta las escasas garantías que las leyes le reconocen". Pensando en la supresión de sindicatos en Italia y Alemania, hizo la analogía con esos países: "No es, en consecuencia, aventurado que esa amenaza entraña otra mayor: la del posible establecimiento de un régimen fascista" 16 .

El expresidente Calles, sin proponérselo, al atacar a Cárdenas facilitó la unificación de las organizaciones laborales. El CNDP se convirtió en un foro al que concurrieron sindicatos que hasta entonces habían estado en polos ideológicos opuestos respecto del Estado y su partido, y se habían manifestado contrarios al apoyo del Estado a las organizaciones sindicales. En realidad, la ruptura entre Calles y Cárdenas, con el apoyo masivo que recibió el presidente del abigarrado movimiento obrero, fue el momento para crear el frente unido laboral, uno de los proyectos del presidente para hacer avanzar la revolución interrumpida por el callismo. Lombardo Toledano estaba seguro de que Calles y su cohorte habían sido derrotados, y que el camino había quedado despejado para crear la central sindical única, así que nada impedía que se ausentara del país ${ }^{17}$.

Formalmente, Lombardo Toledano hizo el viaje en representación de la CGOCM, de la cual era el dirigente máximo, pues consideraba que ésta tenía la "urgencia [...] de conocer de un modo directo la situación que guarda la

\footnotetext{
15 VLT, "El derrumbamiento del general Plutarco Elías Calles", manuscrito, julio de 1935, FHLT, legajo 265; Buchenau, 2007: 174-183.

${ }^{16}$ Consejo Nacional de la CGOCM, "Declaraciones a la prensa", México, D. F., 12 de junio de 1935, FHLT, legajo 265.

17 Middlebrook, 1995: 86-88; vLT, "El derrumbamiento del general Plutarco Elías Calles”, p. 8, manuscrito, julio de 1935, FHLT, legajo 265; Knight, 1994: 73-107.
} 
clase trabajadora en Europa. Esta urgencia es mayor que nunca ante el peligro cada vez más grave de una nueva guerra internacional"18. Lombardo Toledano no sólo creía que representaba a la CGOCM, sino que era la personificación de la clase obrera de México. La idea fue suya: le interesaba hacer el viaje, descansar, pasar por varios países europeos, conocer a Otto Bauer, del ala izquierda de la Segunda Internacional en Praga; visitar los Balcanes, ir a Ginebra, sede de la Organización Internacional del Trabajo, y conversar con los sindicalistas en París y Madrid $^{19}$. Sin embargo, de no haber mediado la recomendación de los comunistas mexicanos ante las autoridades soviéticas, y de no ver los funcionarios de la Internacional Comunista alguna utilidad en su viaje, el periplo no hubiera podido realizarse.

Varios sindicatos colaboraron para sufragar el viaje. Es probable que Lombardo Toledano gestionara ante su amigo Xavier Icaza, ministro de la Suprema Corte de Justicia y secretario de la Universidad Gabino Barreda, precursora de la Universidad Obrera, que alguna secretaría del gobierno colaborara con los gastos de la excursión. Por medio de Gustavo Serrano, secretario de Economía Nacional, consiguió 3000 dólares a cambio de la promesa de un estudio sobre la organización y el funcionamiento de las cooperativas en la URSS y otros países europeos $^{20}$.

\section{EL VIAJE}

Vicente Lombardo Toledano y Víctor Manuel Villaseñor, con sus respectivas esposas, salieron de la ciudad de México el 13 de julio de 1935. Como Lombardo Toledano llevaba un registro preciso de los lugares y el kilometraje recorridos, conocemos su itinerario al detalle; viajaron a Monterrey en tren y a Nueva York en automóvil. Allí se embarcaron a Francia para tocar tierra en Cherburgo el

\footnotetext{
18 "Entrevista para El Machete", México, D. F., 10 de julio de 1935, FHLT, legajo 265.

19 Villaseñor, 1976: 325; VLT a Humberto Lombardo Toledano, México, 10 de julio de 1935, FHLT, legajo 265.

${ }^{20}$ Xavier Icaza a VLT, México, D.F., 31 de julio de 1935, FHLT, legajo 265.
}

1 de agosto. En el camino, Villaseñor abrió una carta que antes de partir le había entregado Luis Cabrera, un viejo amigo de la familia. Cabrera temía la influencia de Lombardo Toledano sobre las opiniones de Villaseñor y le advirtió que mirara la realidad soviética con ojos propios para que el contacto cotidiano con Lombardo Toledano no le produjera "una hipertensión de entusiasmo" y le impidiera ver "claramente la situación de Rusia". La obligación del viajero era "estudiar las condiciones de México a la luz de la situación rusa"(Villaseñor, 1976: 356-358). Villaseñor desdeñó el consejo del viejo político carrancista, pues compartía un sentir generalizado entre los intelectuales progresistas de la época:

\section{El advenimiento de Hitler al poder me había convencido de que la crisis económica mundial habría de conducir a una nueva guerra que, a no dudar, desencadenaría, como conse- cuencia final, movimiento revolucionario en la mayor parte de los países del mundo. Ante la magnitud apocalíptica de los acontecimientos que, según pensaba, advenían a toda prisa, anuncié el próximo derrumbamiento del régimen capita- lista $[y]$ que por primera vez en la historia, uno de los países más atrasados de Europa haya dado el salto al socialismo. (Villaseñor, 1976: 367)}

En realidad, Villaseñor compartía con Lombardo Toledano el enardecimiento por el proceso social y político que se desplegaba en la Unión Soviética. Los viajeros permanecieron dos días en París y tomaron el tren que pasaba por Viena, Praga y Varsovia sin detenerse hasta Negoreloye en Polonia, punto obligatorio para cruzar la frontera hacia la URSS por ferrocarril. Las dos parejas llegaron a Leningrado el 9 de agosto, se quedaron tres días y tomaron el tren a Moscú, donde estuvieron diez días. El itinerario subsiguiente incluyó Jarkov, Baku, Tiflis, Batum, Sujum y Sochi, ciudades industriales y de descanso, que recorrieron en tren y por avión, para regresar a Moscú el 12 de septiembre. En cada uno de los lugares permanecieron de uno a cuatro días. Los viajeros dejaron la Unión Soviética el 17 de septiembre y se dirigieron a Berlín. Excursionaron todavía dos días en París y Madrid, respectivamente, antes de emprender el viaje de regreso a

21 "Itinerario del viaje de los 100 días (13 de julio-20 de octubre) 1935”, FHLT, legajo 265. 


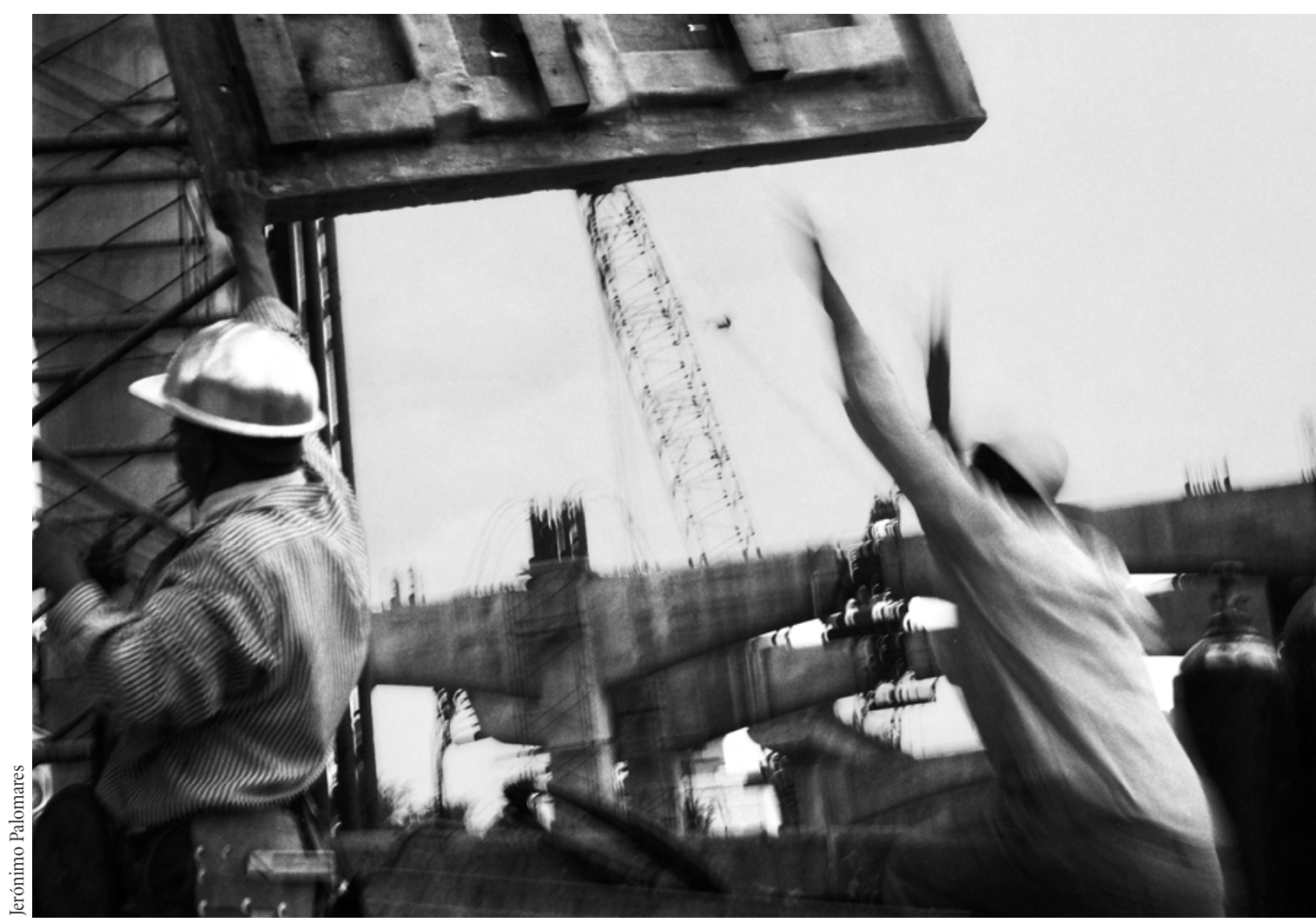

Construcción del segundo piso del Periférico, ciudad de México, 2005.

México, adonde llegaron el 20 de octubre ${ }^{21}$. En sus apuntes, Lombardo Toledano fue preciso al anotar las distancias recorridas, pero exiguo en las descripciones de las ciudades visitadas.

Los viajeros estuvieron en Moscú cuando se realizaba el Séptimo Congreso de la Internacional Comunista, en el cual los dirigentes del Partido Comunista Mexicano eran los delegados. En el Congreso cambió la línea radical de la Comintern — clase contra clase- a una posición moderada de frentes amplios multiclasista en vista del ascenso del anticomunista, antiobrero y antisoviético fascismo. Que Lombardo Toledano estuviera en Moscú en esas fechas no debió haber sido casual sino oportuno para un encuentro con los comunistas mexicanos, y con los dirigentes de la Internacional Comunista como árbitros, para determinar en quién depositaban el papel de la conducción del frente popular en México. Al fin y al cabo, era
Lombardo Toledano, y no los comunistas, quien dirigía a la mayoría de los sindicatos en México, por más vanguardia del proletariado que aquéllos se consideraran. Así se lo hizo saber al dirigente de la Internacional Sindical Roja, Solomon Lozovsky, y a los altos funcionarios de la Internacional Comunista, a quienes detalló los traspiés de los comunistas en su afán de demostrarse contrarios al gobierno popular mexicano y que, por tanto, eran él y la CGOCM los que representaban el frente popular en México. Si bien Lombardo Toledano no se consideraba comunista, aseguró a sus interlocutores soviéticos que "podrían tener la seguridad de que en lo sucesivo será un verdadero defensor de la obra que ha realizado la URSS"22.

\footnotetext{
${ }^{22}$ Memorando de la reunión del 25 de octubre de 1935 del Consejo Nacional de la CGOCM, México, D. F., FHLT, legajo 267.
} 
Los mexicanos cruzaron el país en varias direcciones con "impresiones caleidoscópicas pero precisas que se fundieron en adecuación a mis convicciones", escribió Villaseñor (Villaseñor, 1976: 363), pues encontró un pueblo que "se hallaba en actitud de confianza hacia el futuro que se estaba labrando, que no abrigaba ninguna duda acerca de que sus arduos esfuerzos no significaban una elevación constante de su nivel de vida material y cultural, sino que se traducirían, en un mañana no lejano, en condiciones de existencia colectiva, desconocidas en todos los demás países del mundo" (Villaseñor, 1976: 364). La colectivización forzada y la muerte de millones de campesinos que se resistieron a dejar sus parcelas era un costo invisible para los simpatizantes de la URSS frente a la industrialización que consideraban el verdadero progreso humano. En la Revolución, la violencia era inevitable: "Se incurrió en errores, cometiéronse injusticias y hasta crímenes, qué duda cabe, pero las prodigiosas recompensas de esa revolución [...] no habrían sido posibles de no haber contado los planes quinquenales con el apoyo resuelto y entusiasta de las grandes mayorías" (Vi-
Lombardo Toledano, al mismo tiempo que observaba su alrededor, pensaba en el México que había dejado, confiado en "que sigue el proceso de liquidación del callismo y que el general Cárdenas mantiene su mismo programa de siempre"23. Lombardo Toledano enviaba misivas frecuentes a México sin recibir respuesta. Informaba a los camaradas de los lugares visitados y el monto de kilómetros recorridos, de entrevistas realizadas a los dirigentes sindicales y a los de la Internacional Sindical Roja sin detallar su contenido. Les aseguró que los visitantes podían escoger libremente los lugares y los problemas que les interesaba conocer y que eligieron visitar la Ucrania, el Cáucaso y el Transcáucaso para poder asomarse a la agricultura en gran escala, a la colectivización del trabajo agrícola, a la industria de la maquinaria agrícola, del petróleo, a la agricultura subtropical y el problema de las nacionalidades; informó que los soviéticos pusieron a su disposición "a un camarada inteligente, activo, bien pre-

\footnotetext{
${ }^{23}$ VLT a Tobón, Moscú, 13 de septiembre de 1935. Colección de Manuscritos Generales 238, Archivos Nacionales de Washington, caja 15, exp. 598 .
}

parado en los problemas generales del país y que habla español, y órdenes para usar aviones, trenes, automóviles y barcos" 24 y que al regresar a Moscú esperaba conversar con Stalin y con los dirigentes de la Internacional Comunista:

He hablado con líderes, con obreros distinguidos, con trabajadores de la masa, con intelectuales, con funcionarios públicos. El problema campesino lo he estudiado bien; he visitado numerosas granjas colectivas y granjas del Estado; también varios aspectos muy importantes de su organización. Creo que pocos habrán hecho un viaje como el nuestro; en todas partes he hablado con franqueza completa, exceso de espíritu comunicativo, fraternidad verdadera, espontánea, y gran deseo de conocer en detalle los episodios de nuestras luchas. Me reservo la explicación completa cuando nos veamos; pero he querido desde hoy comunicar a ustedes el éxito de mi viaje, las grandes facilidades que los sindicatos me dieron y la distinción de que he sido objeto por parte de los elementos representativos del proletariado soviético ${ }^{25}$.

Cuando escribió esta carta en septiembre, que nada decía de lo que había visto, Lombardo Toledano todavía pensaba que se quedaría en España un mes para escribir el libro sobre su viaje y regresaría a México a fines de noviembre o diciembre. Urgía que la Confederación se comunicara con él, "informándome de mi familia, pues no hemos recibido sino una carta del día cinco de agosto, y de las novedades de la Confederación pues deseo descansar tranquilo sabiendo que nada importante ocurre en México". Además, le urgía que le enviaran dinero. Pero si estallaba la guerra, Lombardo Toledano regresaría a México inmediatamente, "pues la guerra sería mundial y fuera de Rusia. Mi sitio está en México con ustedes; el momento puede ser decisivo para grandes avances del proletariado" 26 que, sin decirlo, Lombardo Toledano orientaría en la dirección que él consideraba la correcta. Una última indicación:

Si ustedes lo creen conveniente, como yo lo estimo, sería bueno que el Consejo Nacional diera un boletín a la prensa con un resumen de mi viaje dentro de la Unión Soviética,

\footnotetext{
${ }^{24} \mathrm{Idem}$.

${ }^{25}$ Idem. Lombardo Toledano no logró entrevistarse con Stalin.

${ }^{26}$ Idem.
} 
tomando los datos de esta carta, sin decir que ya salí de $\mathrm{Ru}$ sia: simplemente indicando lo que he estudiado hasta hoy, el recorrido hecho, las distinciones de que he sido objeto como representante de la Confederación, y añadiendo que sigo en mi viaje de investigación ${ }^{27}$.

¿Por qué quería Lombardo Toledano que se dijera que seguía en la Unión Soviética cuando ya había partido? ¿Para hacer más creíble la respuesta a cuál era la verdad sobre la URSS?

Una sola respuesta: es tan hermoso ver cómo el socialismo cuaja en realidades, que me hallo absorto, conmovido y dispuesto a redoblar mi trabajo a favor de la revolución proletaria, con más ardor que nunca, con nueva fe, con el estímulo que dan los sueños o las esperanzas que se cumplen. Estoy en el mundo del porvenir ${ }^{28}$.

Lombardo Toledano estaba ansioso de que sus impresiones del viaje llegaran a México a la brevedad posible y empezó a publicar sus artículos semanales en El Universal el 11 de septiembre. Al comparar las observaciones del viaje en el periódico con su itinerario, lo notable es que las hizo desde las ventanillas del tren, desde las estaciones del ferrocarril y a vuelo de pájaro desde el avión. Otros artículos fueron exégesis de la historia rusa comparada con los logros del socialismo soviético, organizado con precisión militar y científica para alcanzar el bienestar de su población. En ningún momento hubo un asomo de crítica (Lombardo Toledano, 1995: 281-317).

Lombardo Toledano y sus acompañantes viajaron de la frontera con Polonia a Leningrado el 8 de agosto en tren de día y noche, pasando por Minsk. El lírico artículo del 18 de septiembre de 1935, titulado "Minsk-Leningrado", publicado en El Universal, empieza así:

El campo está cubierto de trigo maduro. Los segadores levantan la cosecha abriendo grandes surcos en el mar de espigas, con un amplio ritmo de brazos que parecen péndulos vitalmente unidos a las enormes guadañas: en el centro del camino que labra el acero van naciendo los haces de pequeña estatura, como escobas para limpiar el suelo recién descubierto (Lombardo Toledano, 1995: 285).

\footnotetext{
${ }^{27} \mathrm{Idem}$.

${ }^{28} \mathrm{Idem}$.
}

En el artículo sobre Leningrado, Lombardo Toledano fue hiperbólico: "Ni París, ni Berlín, ni Viena producen la impresión de opulencia, de refinamiento, de ostentación y de divorcio con el país que caracteriza a Petrogrado", pues la ciudad, creada por y para los zares, estaba habitada por los ciudadanos de la Revolución, que podían disfrutar de su esplendor como en ninguna otra ciudad imperial (Lombardo Toledano, 1995: 289). En el artículo sobre Moscú, Lombardo aseguró a los lectores que la fiebre de crear y el afán de transformar el pasado dejaron a salvo "las viejas construcciones, derribando las menos útiles, las que carecen de valor histórico artístico" (Lombardo Toledano, 1995: 306). Debió haber sido consciente de que en aras de ensanchar las avenidas de Moscú y alcanzar la grandeza imperial que Stalin le quería imprimir a la capital fueron derrumbados edificios de valor histórico; entre ellos, Stalin mandó destruir la monumental y exquisitamente ornamentada Catedral de Cristo Salvador, abierta al culto en 1883, para en su lugar levantar un Palacio de los Soviets (Figes, 2007: 150). Lombardo Toledano utilizaba en sus artículos frases lapidarias como: "Para la generación que ya tiene en sus manos los destinos de la Unión Soviética, el pasado se resume en Lenin y el futuro cristaliza en Lenin" o "Leningrado es a San Petersburgo lo que el porvenir al presente en los países de régimen burgués" 29 .

Aún se publicaban los artículos en El Universal en noviembre, cuando Lombardo Toledano y Villaseñor exponían sus puntos de vista en una serie de conferencias en las que exaltaban el bienestar de la población trabajadora de la URSS. Decir lo contrario era "la calumnia de los países capitalistas" ${ }^{30}$. Lombardo Toledano presentó al público mexicano a hombres y mujeres soviéticos alegres, felices, cantando y bailando en ronda. En resumen, no quería hacer una fotografía de la Unión Soviética sino dibujar una imagen para persuadir a sus lectores y auditorio de que en el este europeo había amanecido una nueva civilización que con el tiempo envolvería al mundo entero.

29 "Leningrado", El Universal, 30 de octubre de 1935.

30 "La cosecha canta", El Universal, 27 de noviembre de 1935. 


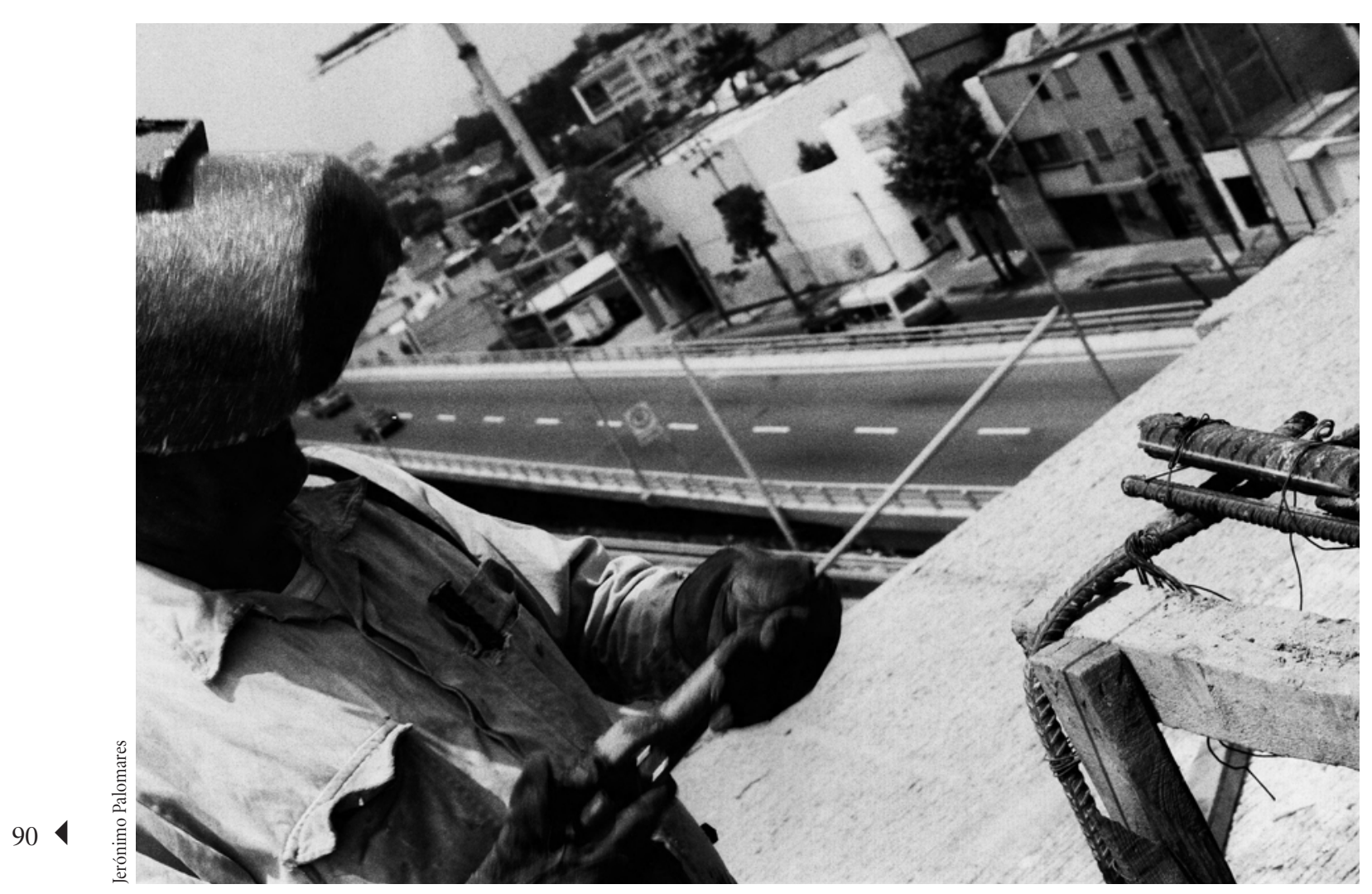

Construcción del segundo piso del Periférico, ciudad de México, 2005.

\section{EL REGRESO DE LA URSS}

Lombardo Toledano tenía programado estar de viaje hasta diciembre pero a finales de septiembre decidió regresar intempestivamente a México, adonde llegó en octubre. Hay varias razones que pueden explicarlo: al empeorar la situación política mexicana, él consideraba necesaria su intervención para favorecer la creación de la central obrera única, con él a la cabeza; es posible que se le acabaran los fondos para permanecer en Europa, y también pudo haber influido el entorno internacional que presagiaba el estallido de la guerra mundial.

La situación en México era tensa por la agresividad de las fuerzas anticardenistas, entre callistas y cromistas que clamaban por el regreso del "jefe máximo" para salvar al país del comunismo. El grupo armado de choque "los Camisas Doradas" reivindicaba "México para los mexi- canos" y no para los ciudadanos del mundo "con el cerebro lleno de teorías insanas y siempre dispuestos a la traición" ${ }^{\text {31 }}$. Hubo brotes de rebeldía en varios estados de la república donde los cardenistas no lograban imponerse en el poder local. Los cristeros y los antiagraristas unieron sus voces al descontento por lo que llamaban la denigración de la bandera nacional por "los cobardes perros soviéticos”. Los maestros rurales eran atacados para que no enseñaran en las escuelas los preceptos de la ideología socialista consignada en la Constitución (Villaseñor, 1996: 367; Bantjes, 1998: 43-46, 60-61; Lerner, 1999: 5867; Hernández Chávez, 1979: 64-75; Vaughan, 1997: 62).

A su regreso a México, Lombardo Toledano reunió a varios dirigentes de las organizaciones que constituían la

31 "Campaña de seis meses que desarrollará Acción Revolucionaria Mexicana Los Dorados”, México, D. F., 1 de diciembre de 1935, FHLT, legajo 269. 


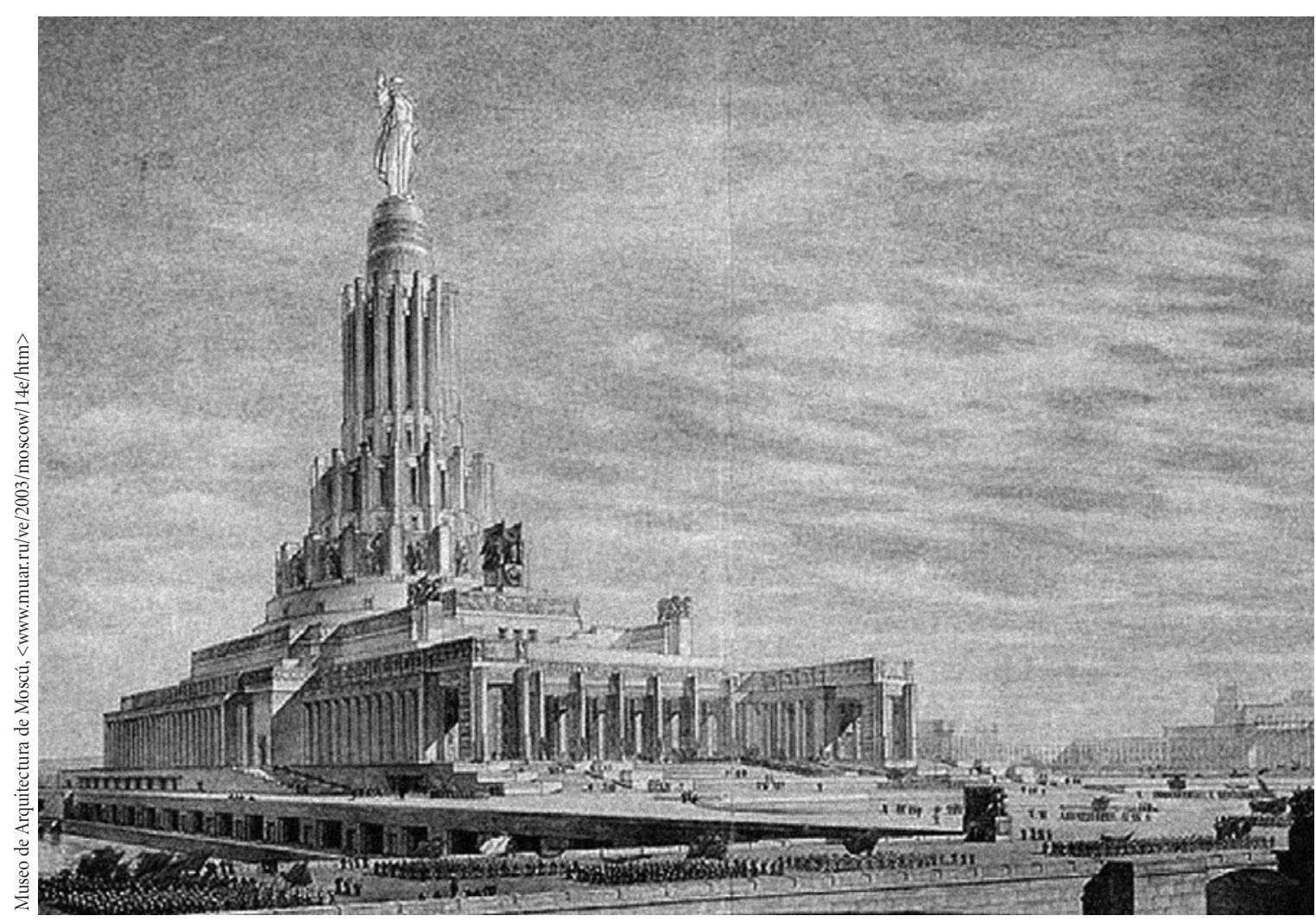

Palacio de los Soviets. Versión aprobada del proyecto, 1946.

CGOCM y enfatizó que en Moscú hizo patente ante los dirigentes soviéticos que los revolucionarios en México no eran los comunistas sino él y sus seguidores en la CGOCM. Lombardo Toledano les describió una Unión Soviética rebosante de entusiasmo constructivo frente a países occidentales con millones de desempleados. Negó que hubiera escasez de infraestructura; mientras que en los países capitalistas sobraba mano de obra por falta de producción, en la URSS faltaba ante tanto ímpetu constructor. La conclusión era evidente: “ ¿Que al existir 50 millones sin trabajo en el mundo forzosamente tendrá que venir la guerra, misma que aprovecharán las masas para hacer la revolución social" 32 . Y para ello había que defender a la Unión Soviética "en cualquier terreno que

\footnotetext{
${ }^{32}$ VLT, México, D. F., 25 de octubre de 1935, FHLT, legajo 267.
}

sea preciso" porque fue allí donde Lombardo Toledano vivió "una hora del mundo del porvenir"; para alentar a sus oyentes a la acción, reforzó su discurso: "[a mi regreso] he visto con alegría profunda que en México se está gestando ya la fuerza que ha de derrumbar pronto el régimen capitalista"33.

Tanto en sus conferencias como en la reunión con los dirigentes de la CGOCM, Lombardo Toledano presentaba un proyecto de nación diferente del proyecto del presidente Cárdenas. Creía que la efervescencia política en México, de cuya resolución consideraba a Cárdenas incapaz, era el momento propicio para encarrilar al país en la dirección deseada, junto con los dirigentes sindicales y los sindicatos simpatizantes.

\footnotetext{
${ }^{33}$ VLT, "Discurso en el Teatro Hidalgo", México, D. F., 7 de noviembre de 1935, FHLT, legajo 268.
} 


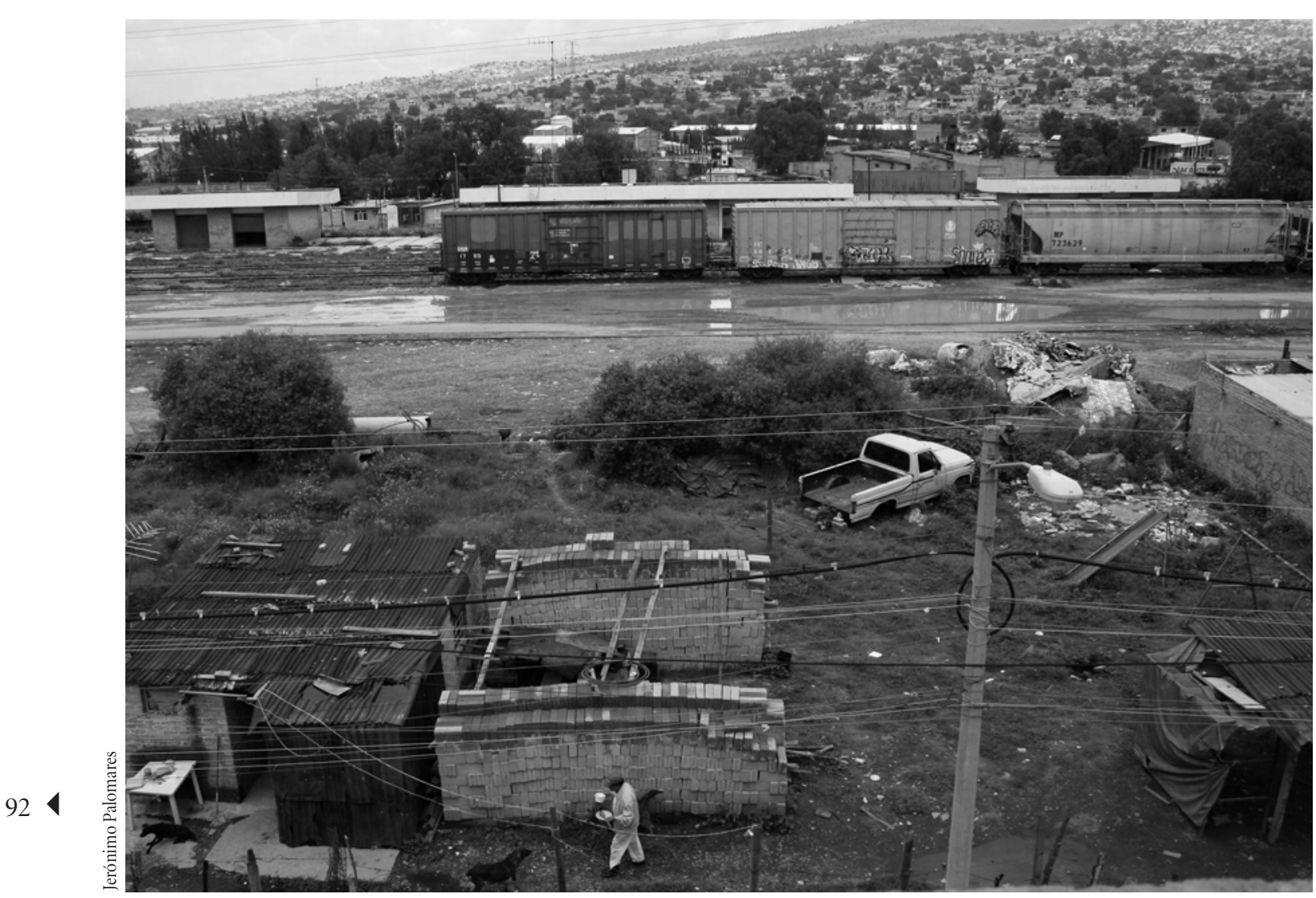

Ciudad perdida.

El ambiente en el que Lombardo Toledano y Villaseñor dieron, en el Teatro Hidalgo, sus conferencias sobre la URSS, "de carácter elemental y didáctico" y no de polémica, y los pronunciamientos de Lombardo Toledanocausaron desconcierto entre sus aliados y furor entre sus adversarios. Lombardo Toledano fue vehemente en sus aseveraciones, contrarias a las noticias que difundía la prensa sobre la Unión Soviética: la población soviética estaba satisfecha de su alimentación, vestimenta y techo. Decir lo contrario eran calumnias de observadores superficiales. Comparada con México, la vida de los trabajadores fabriles y de los campesinos, los servicios proporcionados por el Estado (como la ayuda a las mujeres "de cuerpo ya emancipado"), el nivel de producción y las magníficas construcciones eran "un poderoso ejemplo que tenemos que estudiar con toda aten- ción" 34 . Lombardo Toledano no dejaba lugar a dudas de que: "la democracia capitalista lleva al fascismo y a la guerra; la dictadura del proletariado, para acabar con las clases sociales, lleva a la democracia y a la paz" ${ }^{35}$. Los compañeros en México tenían la palabra, pues el momento era oportuno para la acción ${ }^{36}$.

Las conferencias añadieron leña al fuego. Los periódicos editorializaban sobre la agitación roja y la mano de Moscú. La dirigencia de la CGOCM se asustó ante el radicalismo de Lombardo Toledano, con cuyo proyecto y

\footnotetext{
${ }^{34}$ Lombardo Toledano, "Condiciones actuales de vida del pueblo soviético”, en 1995: 357-396 y Villaseñor, 1996: 361.

${ }^{35}$ Lombardo Toledano, "La estructura política en la URSS", en 1995: 347

${ }^{36}$ VLT, México, D. F., 25 de octubre de 1935, FHLT, legajo 267.
} 
pronóstico del futuro no se identificaba, y por la reacción que sus conferencias suscitaron en el medio político mexicano. Alguien de la dirigencia deslizó este desacuerdo a El Universal, que publicó la noticia del disenso en la cúpula de la CGOCM y de que el Consejo Nacional se deslindó de la propaganda que en favor del comunismo hacía su máximo dirigente. En lo que parecía una lucha ideológica y de posiciones dentro de la organización con proyecciones nacionales e internacionales, Lombardo Toledano reunió al grupo y posiblemente lo obligó a pronunciar un desmentido de que hubiera disenso en su seno; además, pidió a los sindicatos miembros de la Confederación que inundaran la prensa con telegramas en su apoyo. En privado y cuando ya sabía que en unos meses crearía la CTM, Lombardo Toledano, según su compañero de viaje a la URSS, identificó el disenso dentro de la CGOCM con la "herencia del moronismo" con la que "habremos de barrer" (Villaseñor, 1996: 369-370).

Ante los ataques de la prensa, Lombardo Toledano exhortó a la unidad del proletariado, su socorrida consigna, para fortalecer a la organización que planeaba fundar y que debía, por su esperada fuerza, influir en la política del gobierno de Cárdenas. Ante los sindicatos reunidos, Lombardo Toledano estalló contra sus adversarios, cuya derrota no dependía del gobierno que "se considera impotente frente a sus enemigos y frente a los enemigos del pueblo mexicano" sino de la unidad del movimiento obrero junto con el campesino, que el proletariado debía dirigir para que no lo hiciera "la reacción". Y para defenderse de ella:

que en cada Sindical haya un grupo armado para defenderla [aplausos], que en cada comunidad campesina haya también un núcleo armado para defenderla [aplausos]; que cada maestro tenga una escolta de obreros y de campesinos [aplausos]; que cada convoy de pasajeros o cada tren de carga tenga una guardia obrera que respalda a su personal [aplausos]" [y que] "en las ciudades y en los campos los obreros y trabajadores, unificados y armados, defiendan sus intereses sagrados [aplausos]"37.

\footnotetext{
${ }^{37}$ VLT, "Discurso pronunciado en la Arena Nacional", 24 de noviembre de 1935, FHLT, legajo 269.
}

El tono de los periódicos en contra de Lombardo Toledano subió de decibeles después de que en Brasil falló la intentona comunista para tomar el poder ${ }^{38}$, dirigida por el "Caballero de la Esperanza" Luís Carlos Prestes. Los dirigentes de la CGOCM se deslindaron nuevamente de Lombardo Toledano y de sus referencias a las armas: "por no tener el compañero Lombardo ningún puesto de dirección dentro de la CGOCM, resulta inexacto que la dirección de ella haya acordado que se armen los trabajadores" y se deslindaron de cualquier alianza con los dirigentes soviéticos o comunistas ${ }^{39}$.

No sólo la dirección de la CGOCM sino también el presidente Cárdenas se distanció de los designios ideológicos y políticos de Lombardo Toledano. Preocupado por el efecto de sus conferencias y la momentánea colisión dentro de la cúpula obrera, cuya unidad unos meses antes ayudó a fortalecer a su gobierno puesto en entredicho por Calles y sus corifeos, Cárdenas telegrafió a Lombardo Toledano que esperaba apoyo para las obras que llevaba al campo social y político, como la reforma agraria:

Frente al problema social y económico que tiene [el] gobierno, como el de esta Comarca Lagunera y otros más que interesa al propio gobierno resolver y que son en beneficio directo [de las] clases trabajadoras y de la economía general del país, es indispensable ante todo serenar los ánimos y más por aquellos casos que no representan un problema de fondo ${ }^{40}$.

El tiempo apremiaba y no había que distraerse de la cooperación con el gobierno, a la que Lombardo Toledano estaba comprometido desde la crisis de junio de 1935. Cárdenas seguramente era consciente de que el proyecto de Lombardo Toledano y el suyo - la utopía mexicana- (Gilly, 1994) no coincidían, pero confiaba en el sentido político y en el patriotismo del dirigente obrero y en su instinto de no abrir un nuevo frente en un momen-

\footnotetext{
38 "La agitación roja y la mano de Moscú", El Universal, 28 de noviembre de 1935 .

${ }^{39}$ Declaraciones a la prensa, firman Benjamín Tobón y Rubén Magaña, México, D. F., 13 de noviembre de 1935 y Fernando Amilpa, Blas Chumacero, México, D. F., 3 de diciembre de 1935, FHLT, legajo 269.

${ }^{40}$ Lázaro Cárdenas a VLT, tren presidencial San Pedro Coahuila, telegrama, 15 de noviembre de 1935, FHLT, legajo 269.
} 
to agitado del país. La revolución hecha gobierno se topaba con múltiples obstáculos. Entre ellos, la acusación a las organizaciones obreras de querer "la disgregación del propio gobierno" (Cárdenas, 1978: 181). ¿Se dirigía Cárdenas también a Lombardo Toledano en diciembre de 1935 cuando exhortó a los trabajadores organizados a "que mantengan su confianza en que la responsabilidad que yo tengo como jefe del Ejecutivo Federal sigue en pie velando por los intereses de toda la nación, y especialmente por los intereses de la clase trabajadora"? ${ }^{41}$

La agitación de Lombardo Toledano surtió efecto en una de las fuerzas anticromistas en Puebla que exhortaron a la revolución: "La revolución social ha principiado; las doctrinas de nuestro líder y compañero Vicente Lombardo Toledano comienzan a ser un hecho; y debemos prepararnos y disciplinarnos para llegar al triunfo". Esta proclama correspondía a la toma de la hacienda de Menantla, en Atlixco, por la Federación Revolucionaria de Obreros y Campesinos, que creía que acababa de formar el primer soviet campesino de la república ${ }^{42}$. También el exsecretario de Educación Narciso Bassols juzgaba, en un lenguaje algo confuso, que el momento podría ser decisivo y si:

la lucha social se plantea categórica y despersonalizada, como bien puede ser; o si, por lo menos, como también puede suceder, el desenvolvimiento de la pugna da el contenido ideológico la preferencia que se impone y destacan las tendencias de lucha, ya sobrará tiempo para que yo reingrese a la acción y juegue mi papel ${ }^{43}$.

Sin embargo, fue Cárdenas quien prevaleció y quitó el argumento a sus críticos del lado izquierdo, cuyo apoyo necesitaba para aminorar el peso de sus críticos del lado derecho del espectro político en el país. Los maestros tenían la razón al demandar mejores salarios, los campesinos estaban en lo justo cuando demandaban el cum-

\footnotetext{
41 "Discurso del presidente de la república a los trabajadores del país", 22 de diciembre de 1935, México, D. F., Cárdenas, 1978: 182.

42 Manifiesto, Puebla, 11 de diciembre de 1935, FHLT, legajo 270. Para el contexto estatal y nacional en que se desarrollaron esos hechos, véase Crider, 1996

${ }^{43}$ Narciso Bassols a VLT, Madrid, 27 de diciembre de 1935, FHLT, legajo 270 .
}

plimiento de sus derechos ante la sistemática y violenta oposición a la reforma agraria. Cárdenas no temía ir todavía más lejos, pues cumplía:

por medio de la acción pacífica su programa revolucionario y trata de llevar el convencimiento a sus opositores. Pero si la oposición persiste en no hacer caso de la labor de buena fe del gobierno, éste se verá obligado a seguir armando a los campesinos y, en caso necesario, a los obreros para garantizar el reparto de la tierra y defender su disfrute y para hacer efectivo el mejoramiento de la clase trabajadora ${ }^{44}$.

El 13 de diciembre de 1935, Plutarco Elías Calles y Luis N. Morones regresaron de Los Ángeles para "salvar la república” del comunismo que, según ellos el gobierno fomentabay protegía. Nobien aterrizaron en suelo mexicano, se descubrió que entraban armas y parque a Veracruz, y en la casa de Morones fueron encontrados pertrechos de guerra y rifles. El Senado ordenó su arresto (Villaseñor, 1996: 371). Igual que en junio, cuando Calles atacó al movimiento huelguista, en diciembre de 1935 su llegada coaligó a los dirigentes, sindicatos, ejidos y comunidades campesinas en torno a Cárdenas. De nueva cuenta, su presencia contribuyó a consolidar la coalición de Cárdenas.

A su vez, el presidente removió los vestigios del maximato a nivel nacional y estatal. No obstante los cambios efectuados por Cárdenas y la expulsión de Calles en abril de 1936, Lombardo Toledano no dejaba de vaticinar el inevitable derrumbe del sistema capitalista:

La burguesía ha entrado en un reposo de unas cuantas horas, después de haber sido derrotada en su última sublevación política; va a retornar con nuevos bríos adoptando una técnica diversa, pero nosotros ya hemos previsto los actos y los gestos futuros de la clase conservadora; no hay que creer que podemos vivir tranquilos jamás mientras permanece el régimen burgués ${ }^{45}$.

\footnotetext{
${ }^{44}$ Declaraciones del presidente de la república a la prensa nacional, Tenancingo, Estado de México, 9 de diciembre de 1935, Cárdenas, 1978:177-78.

${ }^{45}$ VLT, "Posición del movimiento obrero", México, D. F., 23 de abril de 1936, FHLT, legajo 275.
} 


\section{EPÍLOGO DEL VIAJE}

En febrero de 1937, Lombardo Toledano escribió un artículo corrosivo para refutar el contenido del libro de André Gide sobre su viaje a la Unión Soviética, del que se habían publicado tres traducciones en México. Burlándose de la decepción que el afamado escritor francés sufrió tras su visita a la URSS, Lombardo Toledano redujo el libro a la experiencia de un intelectual exquisito, quien al toparse con la realidad soviética sacó a relucir su falsa visión de la vida. El método para refutar a Gide consistió en entresacar frases de su libro y someterlas a una demoledora crítica fuera de contexto. Lo que finalmente Lombardo Toledano reclamaba a Gide era juzgar a la URSS sin "un método científico", en función de sus gustos, prejuicios, temores y esperanzas ${ }^{46}$.

En este caso, como en sus conferencias, Lombardo Toledano defendió y enalteció a la Unión Soviética porque se identificaba con su sistema, y porque creía que su fortalecimiento vigorizaba su propio proyecto de un México popular, nacionalista, antiimperialista y eventualmente socialista, a la cabeza del cual debía estar una élite que él representaba. Así como los dirigentes soviéticos necesitaban a una persona como Lombardo Toledano para hacer avanzar su proyecto de hegemonía mundial, éste tenía que contar con la anuencia de los soviéticos para que fuera él, y no los comunistas, quien recibiera el apoyo político para su proyecto de control sindical en México y luego en América Latina.

Sin embargo, la idea del futuro del país de Lombardo Toledano en la década de 1930 competía con el proyecto del presidente Cárdenas. En la competencia, el primero tuvo que subordinar su proyecto al del presidente, pero su creencia en la eventual configuración del país y del mundo, de la que la Unión Soviética era la avanzada a seguir, no cambió nunca. Lombardo Toledano no creía en los grandes hombres sino en las fuerzas sociales que encarnaban los trabajadores conducidos por sus dirigentes. Según esta interpretación, tanto el reparto agrario como la expropiación del petróleo en 1938 no eran resultado

\footnotetext{
${ }^{46}$ Lombardo Toledano, "André Gide o el sicólogo perdido en la URSs", 1995 [1937]: 57-70.
}

de la audacia de un hombre o de un grupo, sino de la presión obrera que confirmaba su idea de que una vez organizado el movimiento obrero era una fuerza determinante para influir en el rumbo de los acontecimientos. Veía en el cardenismo la confirmación de su creencia en que las leyes históricas apuntalaban el eventual reemplazo del Estado burgués por uno proletario, cuya dirección descansaría en hombres "que dedicaron su vida a meditar, a estudiar las leyes científicas en virtud de las cuales ocurren los procesos históricos", pues la masa trabajadora "resuelve sus problemas por medio del instinto, por clarividencia" ${ }^{37}$. Este cúmulo de ideas que había adoptado en la década de 1920 y reforzado en la siguiente se convirtió en el credo de Lombardo Toledano por el resto de su vida.

\section{Referencias bibliográficas}

Bantjes, Adrian A.,1998, As if Jesus Walked on Earth: Cardenismo, Sonora, and the Mexican Revolution, Scholarly Resources, Wilmington.

Basurto, Jorge, 1983, Cárdenas y el poder sindical, Era, México.

Berger, Meta, 1935, I Saw Russia, Socialism in the Making, American Friends of the Soviet Union, Nueva York.

Buchenau, Jürgen, 2007, Plutarco Elías Calles and the Mexican Revolution, Lanham, Rowman \& Littlefield, Plymouth.

Cárdenas, Lázaro, 1978, Mensajes, discursos, declaraciones, entrevistas y otros documentos 1928/1940, vol. 1, Siglo XXI, México.

Citrine, Sir Walter, 1936, I Search for Truth in Russia, Routledge, Londres.

Crider, Gregory S., 1996, 'Material Struggles: Workers' Strategies during the 'Institutionalization of the Revolution' in Atlixco, Puebla, Mexico, 1930-1942, tesis doctoral, Department of History, University of Wisconsin-Madison, Wisconsin.

David-Fox, Michael, 2003, "The Fellow Travellers Revisited: The 'Cultured West' through Soviet Eyes", The Journal of Modern History, núm. 75, pp. 300-335.

— 2005, "The 'Heroic Life' of a Friend of Stalinism: Romain Rolland and Soviet Culture", Slavonica, vol. 11, núm. 1, pp. 3-29.

\footnotetext{
${ }^{47}$ Lombardo Toledano, "Convención extraordinaria de la CROM", México, D. F., 12 de marzo de 1933, 1995, tomo II, vol. 4, pp. 59-60.
} 
Dreiser, Theodore, 1928, Dreiser Looks at Russia, H. Liveright, Nueva York.

Engerman, David C., 2006, "John Dewey and the Soviet Union: Pragmatism Meets Revolution”, Modern Intellectual History, núm. 3, pp. 33-63.

Figes, Orlando, 2007, The Whisperers. Private Life in Stalin's Russia, Allen Lane, Londres.

Fitzpatrick, Sheila, 1999, Everyday Stalinism. Ordinary Life in Extraordinary Times: Soviet Russia in the 1930s, Oxford University Press, Oxford.

Frank, Waldo, 1932, Dawn in Russia: the Record of a Journey, Charles Scribner's, Nueva York.

Furet, Francois, 1995, El pasado de una ilusión: ensayo sobre la idea comunista en el siglo XX, Fondo de Cultura Económica, México.

Gide, André, 1936, Back from the ussr, Martin, Secker and Warburg, Londres [orig. Retour de l'ur ss, Gallimard, París].

_- 1937, Afterthoughts: Sequel to Back from the ussr, Martin, Secker and Warburg, Londres.

Gilly, Adolfo, 1994, El cardenismo, una utopía mexicana, Cal y Arena, México.

Hernández Chávez, Alicia, 1979, La mecánica cardenista, El Colegio de México, México.

Knight, Alan, 1994, “Cardenismo: Juggernaut or Jalopy?”, Journal of Latin American Studies, vol. 26, parte 1, pp. 73-107.

Lerner, Victoria, 1999, La educación socialista, El Colegio de México, México.

Lombardo Toledano, Vicente, 1995, Obra histórica-cronológica, tomo II, vol. 4 y tomo III, vols. 3 y 5, Centro de Estudios Filosóficos, Políticos y Sociales Vicente Lombardo Toledano, México.

—_, 1995, Obra histórica-cronológica, tomo II, vol. 4, Centro de Estudios Filosóficos, Políticos y Sociales Vicente Lombardo Toledano, México.
__ y Víctor Manuel Villaseñor, 1935, "Situación de la clase trabajadora de México e impresiones de nuestro viaje a la URSs", París, 2 de octubre, Fondo Histórico Lombardo Toledano (FHLT), legajo 267.

Middlebrook, Kevin, 1995, The Paradox of Revolution: Labor, the State, and Authoritarianism in Mexico, Johns Hopkins University Press, Baltimore y Londres.

Morgan, Kevin, 2006, The Webbs and Soviet Communism, Lawrence \& Wishart, Londres.

Serge, Victor, 1933, "Carta desde Moscú”, Víctor Serge Papers, Beinecke Rare Books and Manuscript Library, Yale University, 1 de febrero de 1933.

Shaw, George Bernard, 1964, The Rationalization of Russia, Bloomington, Indiana.

Siegelbaum, Lewis y Andrei Sokolov, 2000, Stalinism as a Way of Life, Yale University Press, New Haven y Londres.

Van Goethem, Geert, 2000, "Conflicting Interests: The International Federation of Trade Unions, 1919-1945”, en Marcel van der Linden (ed.), The International Confederation of Free Trade Unions, Peter Lang, Berna, pp. 73-163.

Vaughan, Mary Kay, 1997, Cultural Politics in Revolution: Teachers, Peasants, and Schools on Mexico, 1930-1940, The University of Arizona Press, Tucson.

Villaseñor, Víctor Manuel, 1976, Memorias de un hombre de izquierda, Grijalbo, México.

\section{Archivos consultados}

Archivo Estatal Ruso de Historia Sociopolítica.

Archivos Nacionales de Washington.

Fondo Histórico Lombardo Toledano (FHLT). 